\title{
The Effect of Anxiety Towards the Academic Performance of Undergraduate Students in Public Universities in Malaysia
}

\author{
Liew Yi Wen*, Hazalizah Hamzah, Roslinda Mustapha \\ Department of Psychology and Counselling, \\ Faculty of Human Development, Universiti Pendidikan Sultan Idris, \\ Tanjong Malim, Perak, Malaysia \\ *e-mail: d074824@siswa.upsi.edu.my
}

Received: 09 May 2021; Accepted: 18 August 2021; Published: 18 August 2021

To cite this article (APA): Liew, Y. W., Hamzah, H., \& Mustapha, R. (2021). The Effect of Anxiety Towards the Academic Performance of Undergraduate Students in Public Universities in Malaysia. EDUCATUM Journal of Social Sciences, 7(2), 82-94. https://doi.org/10.37134/ejoss.vol7.2.8.2021

To link to this article: https://doi.org/10.37134/ejoss.vol7.2.8.2021

\begin{abstract}
This research is a survey to examine the effects of state/trait anxiety towards academic achievement among undergraduates. This study also examines the mediation effect of academic motivation in these relationships. Furthermore, it also investigates gender differences in state anxiety, trait anxiety, academic motivation, and academic performance among undergraduates of Malaysian public universities. Students. To achieve the purpose of study, 143 undergraduates from public universities in Malaysia were surveyed using State-Trait Anxiety Inventory, Demographic Questionnaire and Academic Motivation Scale-College version. The data for were analyzed using descriptive analysis, independent t-test, regression analysis and Sobel test by through SPSS version 23. This study indicated that there is no direct effect of state anxiety and trait anxiety on academic performance among undergraduates. However, they have indirect effects on undergraduates' academic performance through academic motivation. Furthermore, gender difference was not found to be significant in this study in terms of all the variables involved. For the educational purpose, the influence of academic motivation among undergraduates should be taken into account by various parties such as education providers and policy makers in order to ensure a better academic outcome among undergraduates.
\end{abstract}

Keywords: State anxiety, trait anxiety, academic motivation, academic performance, undergraduates

\section{INTRODUCTION}

There are various definitions of anxiety nowadays which can be defined from overt behaviors to inner emotions of a person (Casado \& Dereshiwsky, 2001, as cited in Ansari, 2015). Tertiary education students are vulnerable to anxiety as they have to move away from their home, overcome financial stressor and academic pressure and lastly they need to adjust themselves with a brand new social environment (Friedman, 2020). Anxiety is important in terms of students' academic aspect as it brings a huge impact in their academic performance. The main effect of anxiety towards academic performance among students will be through impairing their concentration by choosing to attend to threatening stimuli which served as a distraction in their learning process (Nail, Christofferson, Ginsburg, Drake, Kendall, McCracken, Birmaher, Walkup, Compton, Keeton \& Sakolsky, 2015). For the purpose of this study, anxiety will be classified into two construct which are state and trait anxiety (Hodgers, 2015).

Meanwhile, academic motivation was believed to benefit students with their study by the way of their motivational beliefs which can increase their progression in study (Gbollie \& Keamu, 2017). Therefore, there is a possibility for the academic motivation to mediate the impact of anxiety towards academic performance among students. According to Silva, Dorso, Azhar \& Renk (2007), anxiety was found to be predicting students' academic performance by relating to their academic motivation, which showed that academic motivation as a mediator in this relationship. 
Other than that, gender was also known to have attributed a huge impact on variables involved in this study. It was believed that different types of genders possess different level of anxiety as in females possess higher level of both state and trait anxiety (Kurimay, Pope-Rhodius \& Kondric, 2017; Panno, Donati, Milioni, Chiesi \& Primi, 2018; Doğan, 2015). As for the academic motivation among undergraduates, some research proved that it was moderated by their genders in which different academic motivation level was shown between female and male undergraduates in the way of female reported higher level of academic motivation compared to male (Bugler, McGeown \& St ClairThompson, 2015). However, this finding contradicted other research findings which found male and female undergraduates posseing similar academic motivation ( $\mathrm{Li} \&$ Zheng, 2017; Yousefi, Jamshidnejad \& Moatamed, 2018). In terms of academic performance, a number of research found that male and female students scored differently in their academic courses in which females outperformed males in terms of academic performance thus contributed to the gender differences in academic performance among undergraduates (Sheard, 2009; Balkis \& Duru, 2017; Sawhney \& Bansal, 2015).

While anxiety is widely known as a common mental distress which was believed to negatively affect academic performance among students, there are still wide array of research which are opposing this statement through the variable of motivation (Elmelid, Stickley, Lindblad, Schwab-Stone, Henrich \& Ruchkin, 2015; Bailey \& Philip 2015). These studies found that anxiety itself is benefiting students in their academic performance. Other than that, there are lack of study which shows the impact of anxiety pertaining to state and trait anxiety on academic performance. One of the variables in this study academic motivation - is said to be mediating the correspondence between anxiety and academic performance by affecting academic performance among students on the basis of Self-Determination Theory whereby motivation described as a continuum manner which is affecting academic performance among students (Koludrović \& Ercegovac, 2015). However, there are still inadequate research which can be used to support this finding on students in Malaysia as the majority of the previous research were conducted in other countries such as in United State (Keeley, Zayac \& Correia, 2008; Silva, Dorso, Azhar \& Renk, 2007).

The Malaysian Health Ministry statistics shows worsening state of anxiety among students from 2011 to 2016 in Malaysia (Bernama, 2016), which could affect their daily lifestyle by reducing their quality of life. Meanwhile, there are various researche which are highlighting the differences between gender in academic motivation among students (Bugler, McGeown \& St Clair-Thompson, 2015; Yousefi, Jamshidnejad, \& Moatamed, 2018). However, consistency is lacking in the result reported. In terms of academic performance, as we all are aware of, academic performance is different from one generation to the other. Therefore, there is a need to conduct this study to address those issues above.

\section{OBJECTIVE}

This quantitative research was conducted based on research objectives which focused to examine:

a. the contribution of state/trait anxiety towards academic performance among undergraduate students in public universities in Malaysia.

b. the academic motivation as the mediator between state/trait anxiety and academic performance among undergraduate students in public universities in Malaysia.

c. the gender difference in state anxiety among undergraduate students in public universities in Malaysia.

d. the gender difference in trait anxiety among undergraduate students in public universities in Malaysia.

e. the gender difference in academic motivation among undergraduate students in public universities in Malaysia.

f. the gender difference in academic performance among undergraduate students in public universities in Malaysia. 


\section{HYPOTHESIS}

Based on objectives established for this research, several hypotheses were formed and needed to be tested which are:

$\mathrm{H}_{0} 1$ : There is no contribution of state/trait anxiety towards academic performance among undergraduate students in public universities in Malaysia.

$\mathrm{H}_{1} 1$ : There is contribution of state/trait anxiety towards academic performance among undergraduate students in public universities in Malaysia.

$\mathrm{H}_{0} 2$ : The academic motivation is not a mediator between state/trait anxiety and academic performance among undergraduate students in public universities in Malaysia.

$\mathrm{H}_{1} 2$ : The academic motivation is a mediator between state/trait anxiety and academic performance among undergraduate students in public universities in Malaysia.

$\mathrm{H}_{0} 3 \mathrm{a}$ : There is no gender difference in state anxiety among undergraduate students in public universities in Malaysia.

$\mathrm{H}_{1} 3 \mathrm{a}$ : There is gender difference in state anxiety among undergraduate students in public universities in Malaysia.

$\mathrm{H}_{0} 3 \mathrm{~b}$ : There is no gender difference in trait anxiety among undergraduate students in public universities in Malaysia.

$\mathrm{H}_{1} 3 \mathrm{~b}$ : There is gender difference in trait anxiety among undergraduate students in public universities in Malaysia.

$\mathrm{H}_{0} 3 \mathrm{c}$ : There is no gender difference in academic motivation among undergraduate students in public universities in Malaysia.

$\mathrm{H}_{1} 3 \mathrm{c}$ : There is gender difference in academic motivation among undergraduate students in public universities in Malaysia.

$\mathrm{H}_{0} 3 \mathrm{~d}$ : The is no gender difference in academic performance among undergraduate students in public universities in Malaysia.

$\mathrm{H}_{1} 3 \mathrm{~d}$ : The is gender difference in academic performance among undergraduate students in public universities in Malaysia.

\section{CONCEPTUAL FRAMEWORK}

In order to provide an insight on the current research, a conceptual framework was developed. Through this framework, it is expected that those independent variables involved in the current study which are state anxiety and trait anxiety have an impact on the dependent variable which is academic motivation via the mediation of academic motivation among undergraduates from Malaysia public universities. 


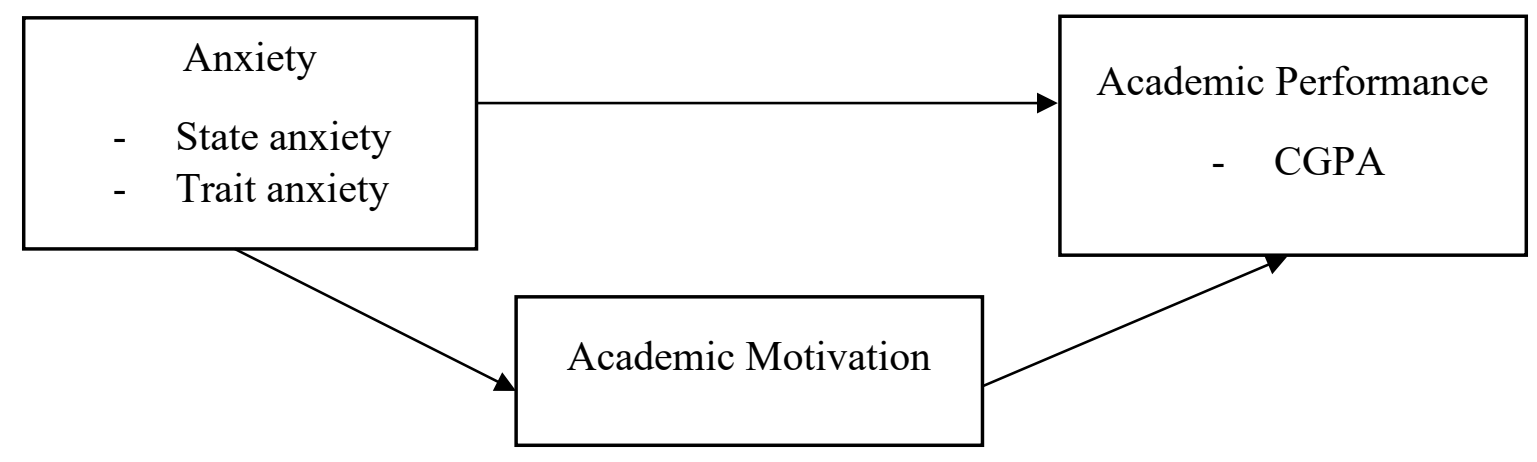

Figure 1: Conceptual Framework of the Study

\section{METHODOLOGY}

\section{Research Design}

This quantitative research implies the method of online survey whereby questionnaire was distributed through internet to the target samples. Besides that, this research is a cross-sectional research which involved 143 undergraduate students as participants. The method applied in order to recruit participants was convenience sampling.

\section{Instruments}

There were 3 different types of instruments included in the online survey questionnaire which were Demographic Information Questionnaire, State-Trait Anxiety Inventory (STAI) and Academic Motivation Scale-College Version (AMS-C28).

The Demographic Information Questionnaire consisted of questions which were aimed to discover unique factors which were related to demographic, such as gender, that might be affecting participants' decisions, opinions and responses. Moreover, The Demographic Information Questionnaire served as a medium to collect data regarding to undergraduates' academic performance in terms of CGPA as participants were required to fill in their latest CGPA as requested in the questionnaire.

The State-Trait Anxiety Inventory (STAI) applied in this study was in the Form Y version which measured state anxiety and trait anxiety with 20 items respectively -40 items in total. Participants were required to answer the questionnaire based on 4-point Likert rating scale. All the 40 items were derived from both positive and negative items with 21 positive items and 19 negative items.

The Academic Motivation Scale-College Version (AMS-C28) consisted of 28 items which were distributed into 7 subscales equally, with 4 items in each subscale. The 7 subscales mentioned here can be classified into intrinsic motivation, extrinsic motivation and amotivation. Responses were rated according to the 7-point Likert scale. There were two sections in this questionnaire which respectively indicated how they feel presently (section A) and how they feel generally (section B). Motivation was assessed in the form of Self-Determination Index (SDI) in order to assess the self-determination motivation with the formula of ( $2 \mathrm{x}$ (IM to know + IM to accomplish + IM to experience stimulation) / $3+$ Identified Regulation $)$ - ((Introjected Regulation + External Regulation) $/ 2+2 \times$ Amotivation).

\section{Procedure}

First of all, type of questionnaire was identified to be included into the google form and every question was set up as required question, together with information which served as inform consent for participants. The google form was then shared to representatives from each public university in Malaysia and via social media by providing them the link to google form. Before answering the 
questionnaire, participants were briefed on their role in the study, possible risks and that they were allowed to withdraw from the study. All the responses were interpreted and analyzed.

\section{Data Analysis}

In order to meet the aim of this study, descriptive analysis and inferential analysis were conducted via SPSS software. Descriptive statistics was tested to analyze the distribution of demographic data collected. Independent t-test was applied to analyze gender differences based on different variables. Other than that, regression analysis was used to examine the effect of anxiety (state anxiety and trait anxiety) towards academic performance. Moreover, the role of mediation of academic motivation between state/trait anxiety and academic performance was be examined by conducting Sobel test.

\section{Results}

For the descriptive analysis, the total score of state anxiety, trait anxiety and academic motivation were sum up. According to Table 1, the mean of state anxiety among respondents is 49.62 with the standard deviation of 11.46. The mean value of trait anxiety is 51.25 with the standard deviation of 11.04 . Next, mean for respondents' academic motivation is 16.85 with standard deviation of 19.65 . In terms of academic performance, the average was found to be 3.60 in terms of CGPA ( $S D=0.33$ ). The minimum and maximum value of each scale can be referred to table 1 .

Table 1: Descriptive Statistics of State Anxiety, Trait Anxiety, Academic Motivation and Academic Performance of Respondents

\begin{tabular}{cccccc}
\hline & $\boldsymbol{N}$ & Min & Max & $\boldsymbol{M}$ & $\boldsymbol{S D}$ \\
\hline CGPA & 143 & 2.50 & 4.00 & 3.60 & .33 \\
AMS & 143 & -32.17 & 55.50 & 16.85 & 19.65 \\
SA & 143 & 21.00 & 78.00 & 49.62 & 11.46 \\
TA & 143 & 26.00 & 77.00 & 51.25 & 11.04 \\
\hline
\end{tabular}

Apart from that, based on Table 2, 22 participants (15.38\%) fell within the range of mild level (20-37) in terms of state anxiety, meanwhile, 26 participants (18.18\%) scored 38-44 which is medium level of state anxiety and 95 participants $(66.43 \%)$ scored within severe level (45-80). Meanwhile for trait anxiety of participants, 23 participants (16.08\%) fell within the range of mild level (20-37) in trait anxiety, as for the score of medium level of trait anxiety (38-44), there are 11 participants $(7.69 \%)$ and 109 participants $(76.22 \%)$ scored within the score of severe level (45-80).

Table 2: Frequency of Participant in Terms of Severity of State Anxiety and Trait Anxiety

\begin{tabular}{lccc}
\hline & Range & $\boldsymbol{F}$ & $\mathbf{\%}$ \\
\hline State Anxiety & Mild (20-37) & 22 & 15.38 \\
& Medium (38-44) & 26 & 18.18 \\
Trait Anxiety & Severe (45-80) & 95 & 66.43 \\
& Mild (20-37) & 23 & 16.08 \\
& Medium (38-44) & 11 & 7.69 \\
& Severe (45-80) & 109 & 76.22 \\
\hline
\end{tabular}

Simple linear regression analysis was carried out to determine the contribution of state or trait anxiety towards academic performance. Preliminary analysis was conducted so that there is no violation of the assumption of linearity and normality. The prediction of the effect of state anxiety towards academic performance among respondents is insignificant, $F(1,141)=1.47, p>0.05$, therefore, the null hypothesis is accepted (refer to Table 3 ). As for trait anxiety, it is also insignificantly predicted academic performance among respondents, $F(1,141)=1.66, p>0.05$, which makes the null hypothesis to be accepted (refer to Table 4). 
The Effect of Anxiety Towards the Academic Performance of Undergraduate Students in Public Universities in Malaysia

Table 3: Summary of ANOVA in Undergraduates' Academic Performance in Terms of State Anxiety

\begin{tabular}{cccccc}
\hline Model & SS & $\boldsymbol{d f}$ & MS & $\boldsymbol{F}$ & $\boldsymbol{p}$ \\
\hline Regression & .16 & 1 & .16 & 1.47 & .23 \\
Residual & 14.85 & 141 & .11 & & \\
Total & 15.01 & 142 & & & \\
\hline
\end{tabular}

Table 4: Summary of ANOVA in Undergraduates' Academic Performance in Terms of Trait Anxiety

\begin{tabular}{cccccc}
\hline Model & SS & $\boldsymbol{d} \boldsymbol{f}$ & MS & $\boldsymbol{F}$ & $\boldsymbol{p}$ \\
\hline Regression & .17 & 1 & .17 & 1.66 & .20 \\
Residual & 14.83 & 141 & .11 & & \\
Total & 15.00 & 142 & & & \\
\hline
\end{tabular}

The adjusted R2 indicated that $-0.00 \%$, in which none of the variance in academic performance can be explained by the variance in state anxiety and trait anxiety (refer to table 5). Both state $(t=-1.21, p>$ $0.001)$ and trait anxiety $(t=-1.29, p>0.001)$ were shown to be a statistically insignificant predictor of academic performance. The regression model suggested that each decrease of state anxiety was not related to an improvement in academic performance with $B$ value $=-0.00$. The same goes to trait anxiety, where each decrease of state anxiety was not related to an improvement in academic performance with $B$ value $=-0.00$ (refer to table 6$)$.

Table 5: Summary of Linear Regression Analysis of State Anxiety, Trait Anxiety and Academic Performance

\begin{tabular}{|c|c|c|c|c|}
\hline Model & $R$ & $R^{2}$ & Adjusted $R^{2}$ & SE \\
\hline 1 & .11 & .01 & -.00 & .33 \\
\hline
\end{tabular}

Table 6: Coefficients for the Contribution of State Anxiety and Trait Anxiety Towards Academic Performance

\begin{tabular}{ccccccc}
\hline & \multicolumn{2}{c}{ Unstandardized Coefficients } & \multicolumn{2}{c}{ Standardized Coefficients } & & $\boldsymbol{t}$ \\
Model & B & SE & Beta & 30.95 & .00 \\
Constant & 3.74 & .12 & & -1.21 & .23 \\
SA & -.00 & .00 & -.10 & 29.13 & .00 \\
Constant & 3.76 & .13 & & -1.29 & .20 \\
TA & -.00 & .00 & -.11 & \\
\hline
\end{tabular}

In order to test the mediation effect of academic motivation between state anxiety and academic performance, a Sobel test and linear regression analysis was run. As the mediator, academic motivation, joined the contribution model of state anxiety on academic performance, it had become a positive significant predictor $(t=3.34, p<0.05)$ towards academic performance with the coefficient of 0.01 . Sobel test was applied to further examine the role of academic motivation as a mediator in the contribution of state anxiety towards academic performance. Result showed it is a statistically significant mediator between state anxiety and academic performance $(t=6.70, p<0.05, \mathrm{SE}=0.07)$ and rejected the null hypothesis. 
Table 7: Coefficient of Relationship Between State Anxiety and Academic Motivation

\begin{tabular}{lccccc}
\hline & \multicolumn{2}{c}{ Unstandardized Coefficients } & \multicolumn{2}{c}{ Standardized Coefficients } \\
Model & B & SE & Beta & $\boldsymbol{t}$ & $\boldsymbol{p}$ \\
\hline (Constant) & 46.24 & 6.90 & & 6.70 & .00 \\
SA & -.59 & .14 & -.35 & -4.37 & .00 \\
\hline
\end{tabular}

Table 8: Coefficient for Relationship Between State Anxiety, Academic Motivation and Academic Performance

\begin{tabular}{cccccc}
\hline \multicolumn{7}{c}{ Unstandardized Coefficients } & \multicolumn{2}{c}{ Standardized Coefficients } \\
Model & B & SE & Beta & $\boldsymbol{t}$ & $\boldsymbol{P}$ \\
\hline (Constant) & 3.52 & .13 & & 26.26 & .00 \\
SA & $-6.40 \mathrm{E}-5$ & .00 & -.00 & -.03 & .98 \\
AMS & .01 & .00 & .29 & 3.34 & .00 \\
\hline
\end{tabular}

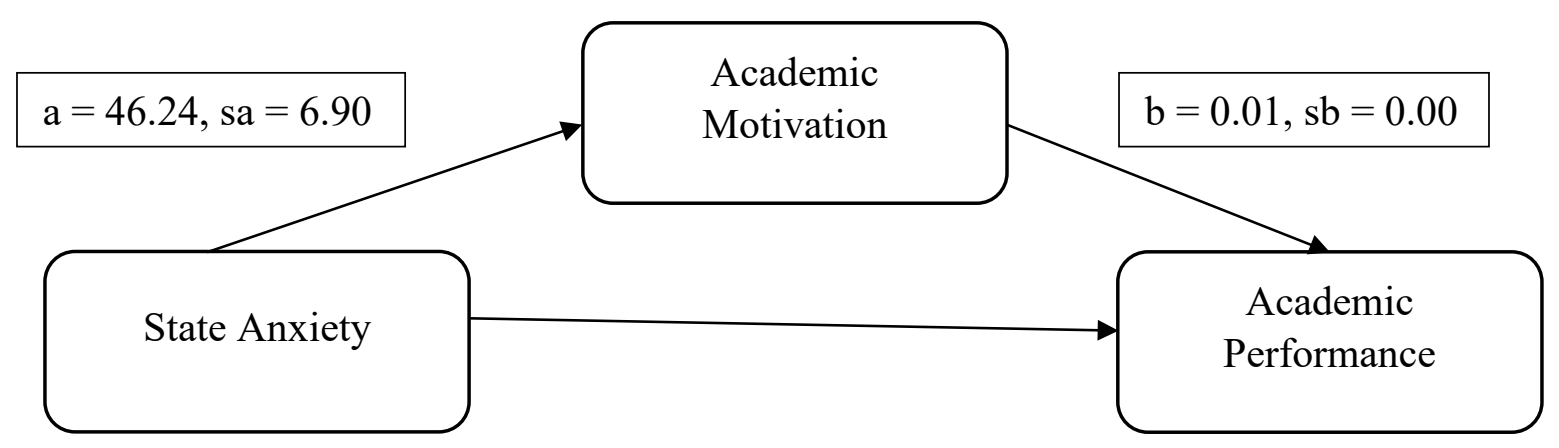

Figure 2. Mediation of Academic Motivation Between State Anxiety and Academic Performance

Table 9: Summary of Sobel Test in Relationship Between State Anxiety, Academic Motivation and Academic Performance

\begin{tabular}{ccc}
\hline Sobel test & $p$-value Sobel test & Std. Error \\
\hline 6.70 & .00 & .07 \\
\hline
\end{tabular}

Next, a Sobel test was conducted in order to analyze the mediation effect of academic motivation between trait anxiety and academic performance. Academic motivation had become a positive significant predictor $(t=3.31, p<0.05)$ towards academic performance with the coefficient of 0.01 as it joined the contribution model of trait anxiety on academic performance. With the further analysis on the mediation role of academic motivation with Sobel test, it was found that there is a significant mediation effect on the contribution of trait anxiety towards academic performance $(t=7.11, p<0.05$, $\mathrm{SE}=0.07)$ and this rejected the null hypothesis.

Table 10: Coefficient for Relationship Between Trait Anxiety and Academic Motivation

\begin{tabular}{lccccc}
\hline \multicolumn{7}{c}{ Unstandardized Coefficients } & \multicolumn{2}{c}{ Standardized Coefficients } \\
Model & B & Std. Error & Beta & $\boldsymbol{t}$ & $\boldsymbol{p}$ \\
\hline (Constant) & 51.64 & 7.26 & & 7.11 & .00 \\
TA & -.68 & .14 & -.38 & -4.90 & .00 \\
\hline
\end{tabular}


The Effect of Anxiety Towards the Academic Performance of Undergraduate Students in Public Universities in Malaysia

Table 11: Coefficient for Relationship Between Trait Anxiety, Academic Motivation and Academic Performance

\begin{tabular}{|c|c|c|c|c|c|}
\hline \multirow[b]{2}{*}{ Model } & \multicolumn{2}{|c|}{ Unstandardized Coefficients } & \multicolumn{3}{|l|}{ Standardized Coefficients } \\
\hline & B & Std. Error & Beta & $t$ & $p$ \\
\hline 1 (Constant) & 3.52 & .15 & & 24.16 & .00 \\
\hline TA & $8.08 \mathrm{E}-5$ & .00 & .00 & .03 & .98 \\
\hline AMS & .01 & .00 & .29 & 3.31 & .00 \\
\hline
\end{tabular}

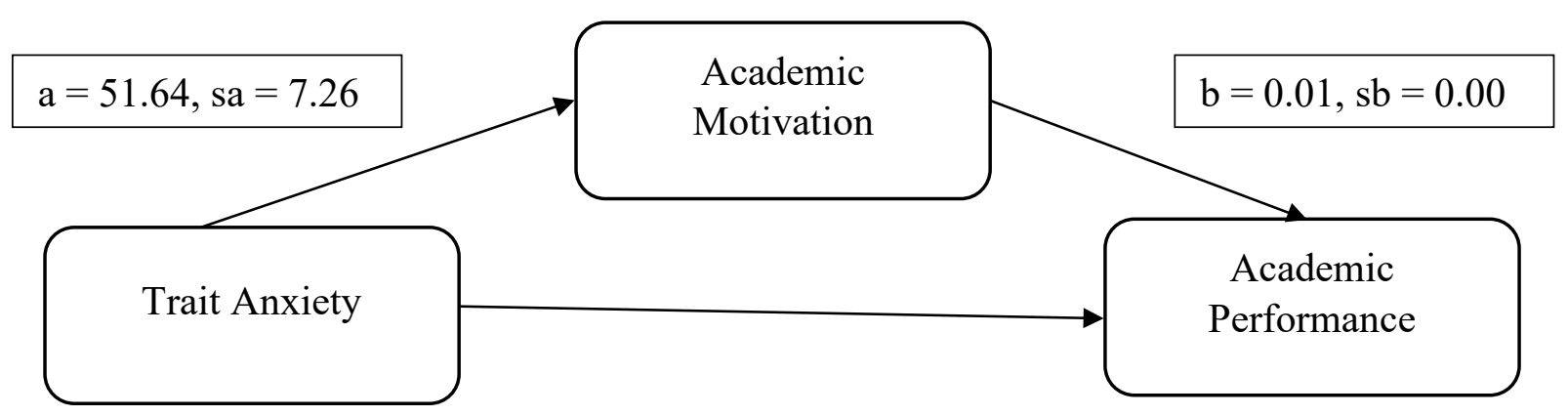

Figure 3: Mediation of Academic Motivation Between Trait Anxiety and Academic Performance

Table 12: Summary of Sobel Test in Relationship Between Trait Anxiety, Academic Motivation and Academic Performance

\begin{tabular}{ccc}
\hline Sobel test & $p$-value Sobel test & Std. Error \\
\hline 7.11 & .00 & .07 \\
\hline
\end{tabular}

An independent t-test was conducted to test the differences between gender for state anxiety, trait anxiety, academic motivation and academic performance. According to table 13, there was no significant difference in the scores of state anxiety in male $(M=49.05, S D=9.64)$ and state anxiety in female $(M=50.05, S D=12.73) ; t(141)=-0.52, p=0.61$. There was also no significant difference in the scores of trait anxiety in male $(M=50.76, S D=10.16)$ and trait anxiety in female $(M=51.63, S D$ $=11.72) ; t(141)=-0.47, p=0.64$. Moreover, there was no significant difference in the scores of academic motivation in male $(M=16.85, S D=17.84)$ and academic motivation in female $(M=16.86$, $S D=21.04) ; t(141)=-0.00, p=1.00$. Lastly, it was found that there was an insignificant difference in the scores of academic performance between male $(M=3.64, S D=0.30)$ and female $(M=3.57, S D=$ $0.34) ; t(141)=1.36, p=0.18$. All of these findings accepted the null hypothesis which stated that there are no gender differences in trait anxiety, state anxiety, academic motivation and academic performance among undergraduate students in public universities in Malaysia.

Table 13: Summary for Independent T-test for State Anxiety, Trait Anxiety, Academic Motivation and Academic Performance Between Gender

\begin{tabular}{cccccccc}
\hline & Gender & $\boldsymbol{N}$ & $\boldsymbol{M}$ & $\boldsymbol{S D}$ & $\boldsymbol{t}$ & $\boldsymbol{d} \boldsymbol{f}$ & $\boldsymbol{p}$ \\
\hline \multirow{2}{*}{ SA } & Male & 62 & 49.05 & 9.64 & -.52 & 141 & .61 \\
& Female & 81 & 50.05 & 12.73 & & & \\
TA & Male & 62 & 50.76 & 10.16 & -.47 & 141 & .64 \\
& Female & 81 & 51.63 & 11.72 & & & \\
AMS & Male & 62 & 16.85 & 17.84 & -.00 & 141 & 1.00 \\
& Female & 81 & 16.86 & 21.04 & & & \\
CGPA & Male & 62 & 3.64 & .30 & 1.36 & 141 & .18 \\
& Female & 81 & 3.57 & .34 & & & \\
\hline
\end{tabular}


Hence, based on the findings, a total of five hypotheses can be rejected which are $\mathrm{H}_{1} 1, \mathrm{H}_{1} 3 \mathrm{a}, \mathrm{H}_{1} 3 \mathrm{~b}, \mathrm{H}_{1} 3 \mathrm{c}$ and $\mathrm{H}_{1} 3 \mathrm{~d}$ whereas the remaining one which is $\mathrm{H}_{1} 2$ is accepted. It was found that state/trait anxiety does not contribute towards academic performance. Apart from that, there is no gender differences in state anxiety, trait anxiety, academic motivation and academic performance. Lastly, academic motivation served as a mediator for contribution of both state anxiety and trait anxiety towards academic performance.

\section{DISCUSSION AND IMPLICATION OF STUDY}

\section{Research Objective 1: To Examine the Contribution of State/Trait Anxiety Towards Academic Performance Among Undergraduate Students in Public Universities in Malaysia.}

Based on the regression analysis conducted, at the $a=0.05$ level of significance, there is no statistically significant linear dependence of the mean of academic performance on state anxiety was detected among undergraduates from public universities in Malaysia which is in accordance with some previous studies (Razak, Yassin \& Maasum, 2017), however, it also rejected findings made by other studies (Stevens, Nussbaum \& Blake, 2019; Macher, Paechter, Papousek, Ruggeri, Freudenthaler \& Arendasy, 2013). This might be due to the fact that undergraduate students who have involved in academic settings for years gained experiences on how to deal with their examination (Razak, Yassin \& Maasum, 2017). Moreover, the effect of anxiety can be different depending on the characteristics of the course taken by undergraduates (Yüksel \& Geban, 2016) which further explains the insignificance of the state anxiety in determining undergraduates' academic performance as this study involved undergraduates from different courses with different characteristic which have different effect towards their state anxiety.

The finding of this study indicated that the variable, trait anxiety among undergraduates from public universities in Malaysia insignificantly predicted their academic performance. This finding is agreeing with the result of previous study (Sesé, Jiménez, Montaño \& Palmer, 2015) which points out the existence of confounding variables such as negative affect of anxiety towards academic and the academic background of undergraduates that will enable the indirect effect of trait anxiety on academic performance to occur. Other than that, different course with different characteristics tend to affect the impact of anxiety towards undergraduates' academic performance and this will be able to explain our study's finding as this study is involving undergraduates from various course (Yüksel \& Geban, 2016). However, some previous studies are rejecting this finding with the result of significant relationship between trait anxiety and academic performance (Justicia-Galiano, Martín-Puga, Linares \& Pelegrina, 2017).

Research Objective 2: To Study Academic Motivation as the Mediator Between State/Trait Anxiety and Academic Performance Among Undergraduate Students in Public Universities in Malaysia.

\section{Contribution of State Anxiety Towards Academic Performance}

With the absence of significant contribution of state anxiety towards academic performance, the mediation analysis can be conducted with the assumption of inconsistent mediation (MacKinnon, Krull \& Lockwood, 2000). The findings of Sobel test indicated that academic motivation is a mediator for the contribution of state anxiety towards academic performance, which is in contrast of the previous study (Keeley, Zayac \& Correia, 2008). This might be due to the research conducted by Keeley, Zayac \& Correia (2008) involving undergraduates who enrolled in statistics course only compared to the current research which involved undergraduates with various course background.

\section{Contribution of Trait Anxiety Towards Academic Performance}

Sobel test was conducted to analyze the mediation effect of academic motivation towards the contribution of trait anxiety towards academic performance. The finding showed that there was an indirect effect of trait anxiety towards academic performance which was mediated by academic motivation among undergraduates in Malaysia public universities and it is the same as previous finding by Silva, Dorso, Azhar and Renk (2007). The results of their study indicated that undergraduates with 
higher anxiety level tended to do poor in their examination. However, undergraduates with higher academic motivation tended to score better. Highly motivated undergraduates tend to be high in selfconfidence, consistency towards a task and focus on their task when they face with challenging task, which helps them in scoring (Balogun, Balogun \& Onyencho, 2017). To be specific, the role of academic motivation is an inconsistent mediation as there is an insignificant direct effect between trait anxiety and academic performance.

Research Objective 3: To Investigate Gender Difference in State Anxiety Among Undergraduate Students in Public Universities in Malaysia

The result of independent t-test indicated that there was no gender difference in terms of state anxiety which is in accordance with previous studies (Habibović, van den Broek, Theuns, Jordaens, Alings, van der Voort \& Pedersen, 2011; Moeller, Salmela-Aro, Lavonen \& Schneider, 2015; Bieg, Goetz, Wolter $\&$ Hall, 2015). This explained that both female and male implied similar effect on the state anxiety, but it contradicted some previous research findings (Kurimay, Pope-Rhodius \& Kondric, 2017; Panno, Donati, Milioni, Chiesi \& Primi, 2018).

\section{Research Objective 4: To Study Gender Difference in Trait Anxiety Among Undergraduate Students in Public Universities in Malaysia.}

Meanwhile, in terms of trait anxiety, male undergraduates were found to excite a similar level of trait anxiety with female undergraduates as in previous researche (Zhang, Wang, Zhu, Yu \& Chen, 2015) which rejected some research (Doğan, 2015; Núñez-Peña, Suárez-Pellicioni \& Bono, 2016; Hill, Mammarella, Devine, Caviola, Passolunghi \& Szücs, 2016). The absence of the gender difference in trait anxiety might be due to undergraduates nowadays were under the same level of academic stress (Mulyadi, Rahardjo \& Basuki, 2016) as the academic stress faced by undergraduates was a precursor of the trait anxiety (Racic, Todorovic, Ivkovic, Masic, Joksimovic \& Kulic, 2017).

\section{Research Objective 5: To Identify the Gender Difference in Academic Motivation Among Undergraduate Students in Public Universities in Malaysia.}

Academic motivation between male and female undergraduates were found to be similar. This finding was similar to previous studies (Yousefi, Jamshidnejad \& Moatamed, 2018; Li \& Zheng, 2017) which was in contrast with the research by Bugler, McGeown \& St Clair-Thompson (2015), which reported that female tended to have higher academic motivation than male. This might be due to the cultural differences in which Bugler, McGeown \& St Clair-Thompson conducted research in United Kingdom which applied Western culture compared to others who conducted research in China and Turkey.

\section{Research Objective 6: To Evaluate Gender Difference in Academic Performance Among Undergraduate Students in Public Universities in Malaysia.}

Academic performance with the representative of CGPA among undergraduates from public universities in Malaysia were found to be similar between male and female which rejected previous studies (Sawhney \& Bansal, 2015; Balkis \& Duru, 2017; Sheard, 2009). This can be explained by the finding of academic motivation with no gender difference as there was a significant relationship between academic motivation and academic performance ( $\mathrm{Wu}, 2019)$.

\section{Limitations}

Unfortunately, this study has some limitations which might influence the overall results. Firstly, online survey form was distributed to all the representative of public universities in Malaysia and over the social media. However, it was found that not every public universities undergraduate students responded to the online survey form provided, which caused the possibility for the findings to be unreliable as every public university has its own specific culture. Other than that, data collection method applied in the current study was online survey which indicated that the majority of the respondents provided information in accordance to the survey form distributed without the supervision of the researcher. This phenomenon gave rises to the possibility of respondents to responds to the survey form without following the rules provided in the survey form. Moreover, there was a limitation encountered by the researchers during the interpretation of data which was lack of previous study to be referred in 
terms of mediation analysis of academic motivation in contribution of state/trait anxiety towards academic performance, causing discussion of the current study difficult to be conducted as the previous study served as a foundation in understanding how the research finding was going to contribute to the relevant field of study. Thus, the researchers might leave out crucial information which can be obtained via the comparison between the previous studies and current study.

\section{Implications}

In this study, it shows the importance to maintain an optimal level of academic motivation among undergraduates. Therefore, policy makers can establish an effective policy by addressing motivational aspect of undergraduates in terms of academic. Next, researchers of related field who are interested in conducting study in the educational aspect can be informed through this study about the role of undergraduates' gender in their academic performance and academic motivation. The results of this study are in contrast with some of the previous studies, therefore, the inconsistency of findings in terms of gender differences in academic performance and academic motivation suggests the need to conduct a relevant research in order to establish more valid and reliable findings which provides an idea for future studies. Furthermore, opportunities exist for researchers from the related field of study to examine the differences between state anxiety and trait anxiety among undergraduates from public universities in Malaysia and their impact on how well an undergraduate student able to do in their academic settings and thus extend the perspective to a more specific types of state anxiety and trait anxiety.

\section{Future Recommendations}

For future research, it is highly recommended to not only include undergraduates from public universities, but also undergraduate students from private universities in Malaysia. The inclusion of undergraduates from private universities in Malaysia is necessary in order to establish an opportunity to examine the overall trend of undergraduates in Malaysia. Furthermore, it is also recommended that the independent variables (state anxiety and trait anxiety) to be specified into a more precise variable such as state statistics anxiety and trait test anxiety for the future research. Moreover, data collection of future research is recommended to be done in the normal survey rather than the online survey. With this, respondents who do not understand any parts of the statement or even instruction can consult the researchers.

\section{CONCLUSION}

As a conclusion, all the result obtained in conjunction of objectives are discussed and explained clearly. It was noted that state/trait anxiety was not related to academic performance of undergraduates from Malaysia public universities, meanwhile, the state anxiety, trait anxiety, academic motivation and academic performance were similar between male and female. Lastly, academic motivation was a mediator for relationship between state/trait anxiety and academic performance. The implication of the current study was stated clearly to advise the potential benefiter of findings. Furthermore, limitations, summary of this study and recommendations for future research was revealed.

\section{REFERENCE}

Ansari, M. S. (2015). Speaking anxiety in ESL/EFL classrooms: A holistic approach and practical study. International Journal of Education Investigation, 2(4), 38-46. Retrieved from https://pdfs.semanticscholar.org/b348/0c4977df6c8c770bbd8c1ae948f9dd604aa2.pdf

Balkis, M., \& Duru, E. (2017). Gender differences in the relationship between academic procrastination, satifaction with academic life and academic performance. Electronic Journal of Research in Educational Psychology, 15(1), 105-125. DOI: http://dx.doi.org/10.14204/ejrep.41.16042 
Balogun, A. G., Balogun, S. K., \& Onyencho, C. V. (2017). Test anxiety and academic performance among undergraduates: The moderating role of achievement motivation. The Spanish journal of psychology, 20. DOI: $10.1017 /$ sjp.2017.5

Bieg, M., Goetz, T., Wolter, I., \& Hall, N. C. (2015). Gender stereotype endorsement differentially predicts girls' and boys' trait-state discrepancy in math anxiety. Frontiers in psychology, 6, 1404. DOI: 10.3389/fpsyg.2015.01404

Bugler, M., McGeown, S. P., \& St Clair-Thompson, H. (2015). Gender differences in adolescents' academic motivation and classroom behaviour. Educational Psychology, 35(5), 541-556. DOI: https://doi.org/10.1080/01443410.2013.849325

Doğan, C. (2015). Self-efficacy and anxiety within an EFL context. Journal of Language and Linguistic Studies, 12(2), 54-65. Retrieved from https://dergipark.org.tr/jlls/issue/36115/405541

Friedman, M. (2020). Anxiety in college students: Signs, symptoms \& treatments. Retrieved from https://www.choosingtherapy.com/anxiety-in-college-students/

Habibović, M., van den Broek, K. C., Theuns, D. A., Jordaens, L., Alings, M., van der Voort, P. H., \& Pedersen, S. S. (2011). Gender disparities in anxiety and quality of life in patients with an implantable cardioverterdefibrillator. Europace, 13(12), 1723-1730. DOI: https://doi.org/10.1093/europace/eur252

Hill, F., Mammarella, I. C., Devine, A., Caviola, S., Passolunghi, M. C., \& Szücs, D. (2016). Maths anxiety in primary and secondary school students: Gender differences, developmental changes and anxiety specificity. Learning and Individual Differences, 48, 45-53. DOI: https://doi.org/10.1016/j.lindif.2016.02.006

Hodges, W. F. (2015). The psychophysiology of anxiety. Emotions and anxiety (PLE: emotion): New concepts, methods, and applications, 12, 175.

Justicia-Galiano, M. J., Martín-Puga, M. E., Linares, R., \& Pelegrina, S. (2017). Math anxiety and math performance in children: The mediating roles of working memory and math self-concept. British Journal of Educational Psychology, 87(4), 573-589. DOI:10.1111/bjep.12165

Keeley, J., Zayac, R., \& Correia, C. (2008). Curvilinear relationships between statistics anxiety and performance among undergraduate students: Evidence for optimal anxiety. Statistics Education Research Journal, 7(1). Retrieved from http://iase-web.org/documents/SERJ/SERJ7(1)_Keeley.pdf

Kurimay, D., Pope-Rhodius, A., \& Kondric, M. (2017). The relationship between stress and coping in table tennis. Journal of human kinetics, 55(1), 75-81. DOI: 10.1515/hukin-2017-0007

Li, S., \& Zheng, J. (2017). The effect of academic motivation on students' English learning achievement in the eSchoolbag-based learning environment. Smart Learning Environments, 4(1), 3. DOI: 10.1186/s40561017-0042-x

Macher, D., Paechter, M., Papousek, I., Ruggeri, K., Freudenthaler, H. H. \& Arendasy, M. (2013). Statistics anxiety, state anxiety during an examination, and academic achievement. British Journal of Educational Psychology, 83(4), 535-549. DOI:10.1111/j.2044-8279.2012.02081.x

MacKinnon, D. P., Krull, J. L., \& Lockwood, C. M. (2000). Equivalence of the mediation, confounding and suppression effect. Prevention science, 1(4), 173-181. DOI: https://doi.org/10.1023/A:1026595011371

Moeller, J., Salmela-Aro, K., Lavonen, J., \& Schneider, B. (2015). Does anxiety in science classrooms impair math and science motivation? Gender differences beyond the mean level. International Journal of Gender, Science and Technology. Retrieved from https://helda.helsinki.fi/bitstream/handle/10138/232935/398_2935_1_PB.pdf?sequence=1

Mulyadi, S., Rahardjo, W., \& Basuki, A. H. (2016). The role of parent-child relationship, self-esteem, academic self-efficacy to academic stress. Procedia-Social and Behavioral Sciences, 217, 603-608. DOI: $10.1016 /$ j.sbspro.2016.02.063

Núñez-Peña, M. I., Suárez-Pellicioni, M., \& Bono, R. (2016). Gender differences in test anxiety and their impact on higher education students' academic achievement. Procedia-Social and Behavioral Sciences, 228, 154-160. DOI: 10.1016/j.sbspro.2016.07.023

Panno, A., Donati, M. A., Milioni, M., Chiesi, F., \& Primi, C. (2018). Why women take fewer risk than men do: The mediating role of state anxiety. Sex Roles, 78(3-4), 286-294. DOI: 10.1007/s11199-017-0781-8

Racic, M., Todorovic, R., Ivkovic, N., Masic, S., Joksimovic, B., \& Kulic, M. (2017). Self-perceived stress in relation to anxiety, depression and health-related quality of life among health professions students: A cross-sectional study from Bosnia and Herzegovina. Slovenian Journal of Public Health, 56(4), 251-259. DOI: $10.1515 /$ sjph-2017-0034

Razak, N. A., Yassin, A. A., \& Maasum, T. N. R. B. T. (2017). Effect of foreign language anxiety on gender and academic achievement among Yemeni University EFL students. English Language Teaching, 10(2), 7385. DOI:10.5539/elt.v10n2p73

Sawhney, N., \& Bansal, S. (2015). Metacognitive awareness of undergraduate students in relation to their academic achievement. The International Journal of Indian Psychology, 3(1), 107-114. Retrieved from https://pdfs.semanticscholar.org/679f/7912211bf7f65cf616c6bb0ae384005fd91a.pdf 
Sesé, A., Jiménez, R., Montaño, J. J., \& Palmer, A. (2015). Can attitudes towards statistics and statistics anxiety explain students' performance. Revista de Psicodidáctica, 20(2), 285-304. DOI: 10.1387/RevPsicodidact. 13080

Sheard, M. (2009). Hardiness commitment, gender, and age differentiate university academic performance. British Journal of Educational Psychology, 79(1), 189-204. DOI: https://doi.org/10.1348/000709908X304406

Silva, M., Dorso, E., Azhar, A., \& Renk, K. (2007). The relationship among parenting styles experienced during childhood, anxiety, motivation, and academic success in college students. Journal of College Student Retention: Research, Theory \& Practice, 9(2), 149-167. DOI: https://doi.org/10.2190/CS.9.2.b

Stevens, R., Nussbaum, R., \& Blake, T. (2019). Evaluating state anxiety levels in nursing students. Retrieved from https://ideaexchange.uakron.edu/honors_research_projects/815

$\mathrm{Wu}$, Z. (2019). Academic motivation, engagement, and achievement among college students. College Student Journal, 53(1), 99-112. Retrieved from http://search.ebscohost.com.ezpustaka2.upsi.edu.my/login.aspx?direct=true\&db=s3h\&AN=136193466 \&site=ehost-live

Yousefi J. A., Jamshidnejad, A., \& Moatamed, N. (2018). Evaluation of relationship between academic motivation and achievement in students of Zanjan University of Medical Sciences. Journal of Medical Education, 11(29), 54-62. Retrieved from http://zums.ac.ir/edujournal/article-1-892-en.pdf

Yüksel, M., \& Geban, Ö. (2016). Examination of science and math course achievements of vocational high school students in the scope of self-efficacy and anxiety. Journal of Education and Training Studies, 4(1), 88100. DOI:10.11114/jets.v4i1.1090 